\title{
Severity of Stress in Acne Patients Attending Dermatology Outpatient Department of Tertiary Hospital in Kathmandu
}

\author{
Amrita Shrestha', Dinesh Binod Pokhrel², Sudip Parajuli², Manisha Chapagain ${ }^{3}$, Rabina Shrestha ${ }^{4}$ \\ 'Department of Dermatology, Kanti Childrens' Hospital, Maharajgunj, Kathmandu; 'Department of Dermatology, \\ Institute of Medicine, Maharajgunj Medical Campus, Maharajgunj, Kathmandu; ${ }^{3}$ Department of Psychiatry and Mental \\ Health, Institute of Medicine, Maharajgunj Medical Campus, Maharajgunj, Kathmandu, ${ }^{4}$ Department of Research and \\ Development, Dhulikhel Hospital, Kathmandu University, Dhulikhel
}

\begin{abstract}
Introduction: Stress persists when a person is unable to cope with the situations of the past, present or future. Stress may be associated with physical and psychological abnormalities. Acne vulgaris is a chronic inflammatory disease of the pilo-sebaceous units with prevalence of more than $85 \%$ in adolescent age group.

Materials and Methods: Three hundred one patients were recruited in the study. Inclusion criteria included new acne patients of age 16 years and above as well as those who were using but not improving with topical or oral acne therapies. Exclusion criteria included patients receiving sedatives, antidepressants, or glucocorticoids, patient suffering from chronic illnesses like diabetes, hypothyroidism, chronic kidney disease, migraine and other diseases. This questionnaire included biodata of the patients, clinical history and their perceived stress scale. Global Acne Grading System (GAGS) was used to assess acne severity in relation to stress using the Perceived Stress Scale (PSS).

Results: The results indicated an increase in stress severity positively correlated with an increase in acne severity, which was statistically significant $(p<0.01)$. Most of the patients were students. Subjects with higher stress scores, determined using the PSS, had higher acne severity when examined and graded using the GAGS.

Conclusions: The results showed that there is a positive correlation between severity of stress and grade of acne. Stress management should be a part of acne management.
\end{abstract}

Key words: Acne Vulgaris, Stress, Acne severity, Acne Grade, Stress scale

\section{Introduction}

A cne is a skin disease that mainly affects the face and upper torso. These regions of skin are densely populated by sebaceous glands (SGs), which are cutaneous appendages that secrete lipids in the form of sebum. ${ }^{1}$ It is a chronic inflammatory disease of the pilo-sebaceous units. ${ }^{2}$ It is a common cutaneous inflammatory disorder affecting more than $85 \%$ of adolescents worldwide. Its pathogenesis is multifactorial. One of the factors is stress, which influences several dermatological disorders. ${ }^{3}$ Psychological stress can be a precipitating factor for acne exacerbation.

Funding: No

Conflict of Interest: No

\section{Address of Correspondence}

Dr. Amrita Shrestha, MD

ORCID ID: 0000-0002-1220-5500

Consultant, Department of Dermatology, Kanti Childrens Hospital, Maharajgunj, Kathmandu, Nepal,

Mobile No.: 9851213389

E-mail: amritashrestha08@gmail.com
An interventional study found that patients had an improvement in their acne compared to controls when receiving biofeedback training, relaxation training, and stress reduction techniques. ${ }^{4}$ The acne patients reported levels of social, psychological and emotional problems that were as great as those reported by patients with chronic disabling asthma, epilepsy, diabetes, back pain or arthritis. ${ }^{5}$

Date of Submission: $3^{\text {rd }}$ June, 2021

Date of Acceptance: $12^{\text {th }}$ August 2021

Date of Publication: $1^{\text {st }}$ October 2021

How to cite this article

Shrestha A, Pokhrel DB, Parajuli S, Chapagain M, Shrestha R. Severity of Stress in Acne Patients Attending Dermatology Outpatient Department of Tertiary Hospital in Kathmandu. NJDVL 2021;19(2):22-5. https://doi.org/10.3126/njdvl.v19i2.31004.

Licensed under CC BY 4.0 International License which permits use, distribution and reproduction in any medium, provided the original work is properly cited. 
Although there is a widespread acceptance of a relationship between stress and acne flares, only few studies have been conducted. This study has used the Global Acne Grading System (GAGS) to assess acne severity in relation to stress by using the Perceived Stress Scale (PSS). ${ }^{6,7}$

\section{Materials and Methods}

A total of 301 patients visiting the Department of Dermatology, Venereology and Leprology, Tribhuvan University Teaching Hospital, Maharajgunj Medical Campus, Kathamandu, Nepal for treatment of acne agreed to participate in the study. The study was conducted for 6 months period. Sample size was calculated from previous studies ${ }^{8}$ using the formula ( $(Z \alpha=Z \beta) / C$, where $\alpha=$ threshold probability for rejecting null hypothesis type I error rate and $\beta+$ probability of reject null hypothesis under the alternative hypothesis type II error rate, $r=$ Corrrelation coficient , $Z=$ Standard Deviation and $C=0.5 * \ln (1+r) /(1-r)$.

Also $10 \%$ Inclusion criteria included new response rate was added. Acne patients of age 16 years and above and those who were using but not improving with topical or oral acne therapies. Exclusion criteria included all patients receiving sedatives, antidepressants, or exogenous glucocorticoids, patients suffering from chronic illnesses like diabetes, hypothyroidism, chronic kidney disease, migraine and other diseases. Written informed consent was obtained from all patients. Ethical clearance numbered $46(6-11-E)^{2}$ was obtained from the Institutional Ethical Review Committee of Institute of Medicine, Maharajgunj Medical Campus, Tribhuvan University Teaching Hospital, Kathmandu, Nepal.

Perceived Stress Scale (PSS) was used to measure the degree to which the respondents' external situation is perceived as being stressful with higher scores indicating higher levels of perceived stress. This selfquestionnaire is reliable and has been widely used in stress research. ${ }^{9,10}$ This self-administered questionnaire included biodata of the patients: age, gender, occupation, address, clinical history and their PSS. Also the perceived stress severity was calculated. The PSS is divided into very low, low, average, high and very high with scores 0 , 8-11, 12-15, 16-20 and >21 respectively. Upon completion of questionnaires, grading of acne severity was done using Global Acne Grading Scale (GAGS) into mild, moderate, severe and very severe. The score for mild is $1-18$, moderate $19-30$, severe 31-38 and very severe $>39$. The data obtained were entered into a Microsoft Excel 2013. Shapiro-Wilk tests were performed for testing the normality. Since the assessments were done based on scores, and the scores were not normally distributed, nonparametric methods were used for the analysis. Standard descriptive statistical calculations were computed for all the variables. Correlation analysis between PSS and GAGS was performed using Spearman's Correlation. Statistical analysis was done using Statistical Package for the Social Sciences for Windows 7.

\section{Results}

A total of 301 patients (107 men and 194 women, mean age $22 \pm 3.8$ years) were included in the study.

Using the GAGS, it was found that 157 patients (52.2\%) had mild acne, 130 patients (43.2\%) had moderate acne, 4 patients (1.3\%) had severe acne and 10 patients (3.3\%) had very severe acne. PSS showed that 163 patients $(54.2 \%)$ had very high perceived stress, 127 patients $(42.2 \%)$ had high stress, 5 patients $(1.7 \%)$ had average stress, 4 patients (1.3\%) had low stress and 2 patients $(0.7 \%)$ had very low stress.

An increase in stress severity was positively correlated with an increase in acne severity, which was statistically significant $(r=0.242 ; p<0.01)$ but the strength of correlation was very weak. Subjects with higher stress scores, determined using the PSS, had higher acne severity as graded by GAGS. Figure 1 shows scatter diagram showing correlation between GAGS and PSS.

Bold circles in scatter diagram mean some cases have same values of GAGS as well as PSS resulting in overlapping circles.

\section{Discussion}

This study was done among 301 patients visiting Dermatology outpatient with complaints of acne. Our study intended to find the grade and the perceived stress among them. In our study, patients with higher scores of perceived stress determined by using PSS had a higher acne grade, which was found using GAGS. There was a positive correlation $(p<0.01)$. Stress could be both the cause and the effect of severe acne. High level of stress may be work related or related to and academic life. ${ }^{11}$ Similar types of results were found in previous studies. ${ }^{12,13}$

Our study found that $54.2 \%$ of the patients had a very high stress level according to PSS, which was different from the findings of a study done by Do JE et al which showed that $13.8 \%$ had high stress level. ${ }^{14}$ According to the study done by Khunger $\mathrm{N}$ et al, among 280 


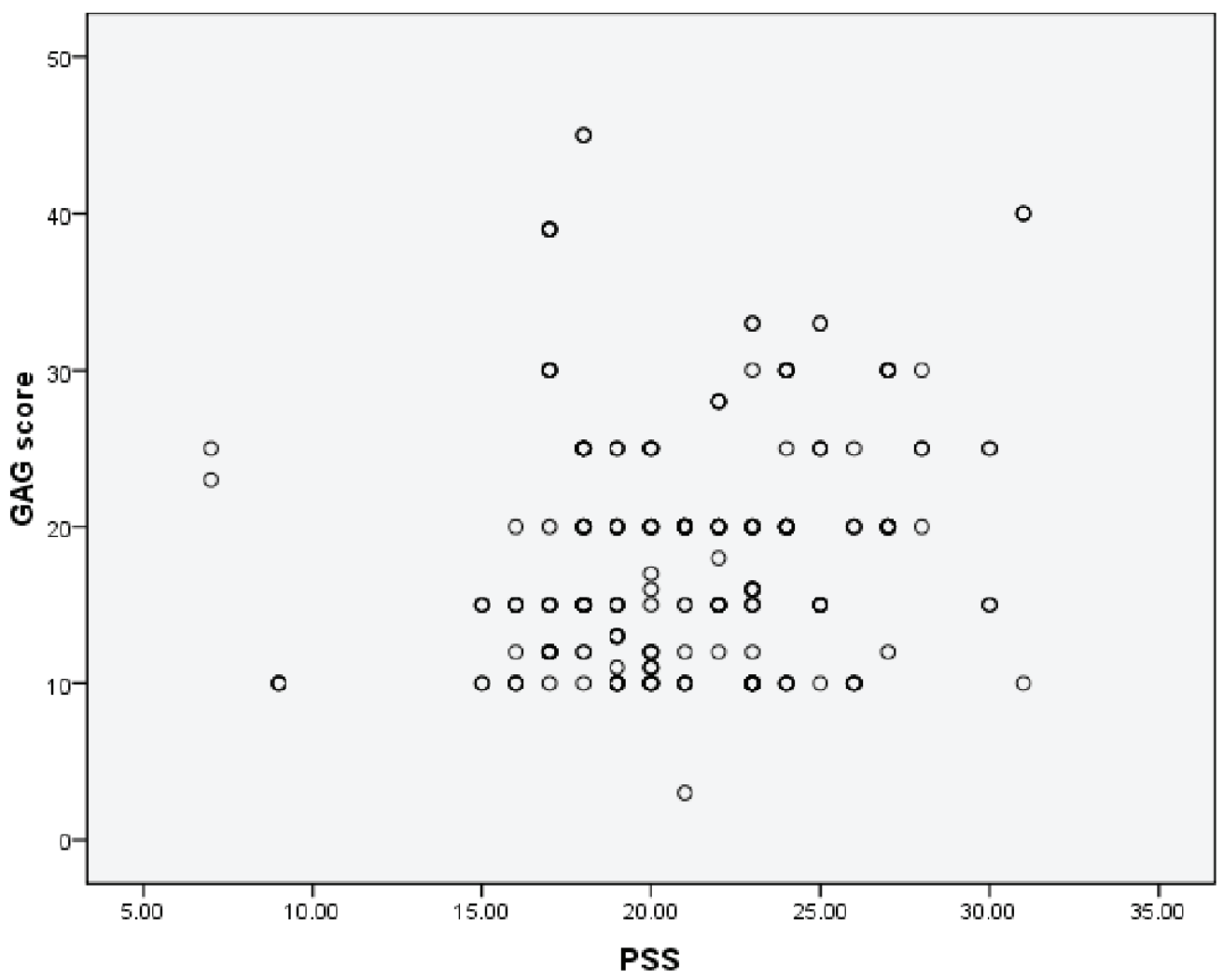

Figure 1: Scatter diagram showing correlation between GAGS and PSS

patients over the age of 25 years presenting with acne in a tertiary care hospital, psychological stress was seen in $52.8 \%$ patients. $^{12}$

In our study, most of the patients with mild acne had high levels of stress. Most of the patients were students and academic related stress may be the main cause of stress. This study showed very weak positive correlation between severity of stress and acne, which was statistically significant $(r=0.242, p<0.01)$. According to a study done by Poli $\mathrm{F}$ et al, stress was recorded as causing acne in $50 \%$ of women. ${ }^{15}$

Another study done by Chiu A et al showed that changes in acne severity correlate highly with increasing stress, suggesting that emotional stress from external sources may have a significant influence on acne. ${ }^{13}$
To the best of my knowledge, there are no studies done in Nepal with respect to relationship of acne with stress. Limitations of the study are small sample size; study included both new acne and old acne cases not responding to topical and oral drug

\section{Conclusions}

The results of this study indicated that there is positive correlation between severity of stress and grade of acne. Therapeutic approaches can be adjusted according to stress levels and behavioral intervention like relaxation therapy could be an option in some cases. It is also necessary to take psychosocial factors into account in the therapy of acne patients.

\section{References}

1. Clayton RW, Göbel K, Niessen CM, R Paus, M A $M$ vaan Steensel, $X$ Lim. Homeostasis of the sebaceous gland and mechanisms of acne pathogenesis. British Journal of Dermatology 2019 Oct; 181(4): 677-690. https://doi.org/10.1111/ bjd.17981

2. Simpson NB CW. Disorders of sebaceous glands. In: Burns T, Breathnach S, Cox N, Griffiths C, editors. In: Rook's Textbook of Dermatology, 7th ed., Oxford: Blackwell Publishing; 2012, pp. 43.143.75.

3. Garg A, Chren MM, Sands LP, Matsui MS, Marenus KD, Feingold KR, et al. Psychological 
stress perturbs epidermal permeability barrier homeostasis: implications for the pathogenesis of stress-associated skin disorders. Arch Dermatol. 2001 Jan; 137(1): 53-9. https://doi.org/10.1001/ archderm.137.1.53

4. Hughes H, Lawlis GF, Brown BW, Fulton Jr JE. Treatment of acne vulgaris by biofeedback relaxation and cognitive imagery. J Psychosom Res 1983; 27:185-191 https://doi.org/10.1016/00223999(83)90021-1

5. Mallon E, Newton JN, Klassen A, Stewart-Brown SL, Ryan TJ, Finlay AY. The quality of life in acne: A comparison with general medical conditions using generic questionnaires. Br J Dermatol 1999; 140: 672-676. https://doi.org/10.1046/j.13652133.1999.02768.x

6. Cohen S, Kamarck T, Mermelstein R. A global measure of perceived stress. J Health Soc Behav 1983; 24: 385-396. https://doi. org $/ 10.2307 / 2136404$

7. Doshi A, Zaheer A, Stiller MJ. A comparison of current acne grading systems and proposal of a novel system. Int J Dermatol 1997; 36: 416-419. https://doi.org/10.1046/j.13654362.1997.00099.x

8. Zari S, Alrahmani D. The association between stress and acne among female medical students in Jeddah, Saudi Arabia. Clin Cosmet Investig Dermatol. 2017 Dec 5;10:503-506. https://doi. org/10.2147/CCID.S148499.
9. Linn MW. Modifiers and Perceived Stress Scale. J Consult Clin Psychol. 1986 Aug; 54(4): 507-13. https://doi.org/10.1037/0022-006X.54.4.507

10. Jović A, Marinović $B$, Kostović $K$, Ceovic R, BastaJuzbasic A, Mokos ZB. The Impact of Pyschological Stress on Acne. Acta Dermatovenerol Croat 2017; 25: 1133-1141.

11. Khunger N, Kumar C. A clinico-epidemiological study of adult acne: Is it different from adolescent acne. Indian J Dermatol Venereol Leprol 2012; 78: 335-341. https://doi.org/10.4103/03786323.95450

12. Yosipovitch G, Tang M, Dawn AG, Chen M, Goh CL, Huak $Y$, et al. Study of psychological stress, sebum production and acne vulgaris in adolescents. Acta Derm Venereol 2007; 87: 135-9. https://doi. org/10.2340/00015555-0231

13. Chiu A, Chon SY, Kimball AB. The response of skin disease to stress: Changes in the severity of acne vulgaris as affected by examination stress. Arch Dermatol 2003; 139: 897-900. https://doi. org/10.1001/archderm.139.7.897

14. Do JE, Cho SM, In S II, Lim KY, Lee S, Lee ES. Psychosocial aspects of acne vulgaris: A community-based study with Korean adolescents. Ann Dermatol 2009; 21: 125-129. https://doi. org/10.5021/ad.2009.21.2.125

15. Poli F, Dreno B, Verschoore M. An epidemiological study of acne in female adults: Results of a survey conducted in France. J Eur Acad Dermatology Venereol 2001; 15: 541-545. https://doi. org/10.1046/j.1468-3083.2001.00357.x 